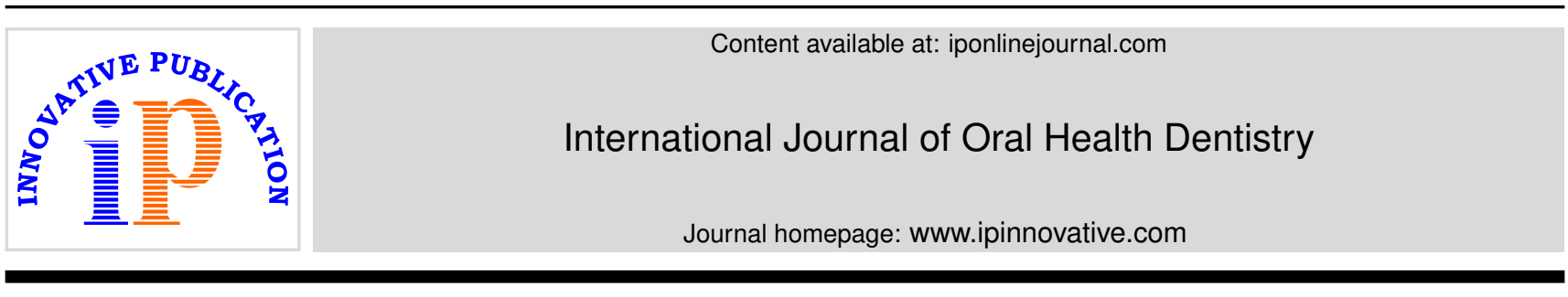

Original Research Article

\title{
Clinical efficacy of a probiotic fluoride dentifrice: A comparitive clinical and microbiologic study
}

\author{
Jasjit Kaur1,*, Rahul Paul², Divya Gupta², Aastha Manchanda², Geetika Arora² \\ ${ }^{1}$ Purexa Global Pvt Ltd, East of Kailash, New Delhi, India \\ ${ }^{2}$ Inderprastha Dental College \& Hospital, Ghaziabad, Uttar Pradesh, India
}

\section{A R T I C L E I N F O}

\section{Article history:}

Received 20-05-2020

Accepted 25-05-2020

Available online 21-07-2020

\section{Keywords:}

Probiotic

Streptococcus mutans

Dentifrice

\begin{abstract}
A B S T R A C T
Introduction: Oral cavity harbors wide variety of microorganisms; these are considered crucial for the dental caries initiation and progression. Plaque-induced caries is a local disease; therefore, dentifrices are the most ideal vehicle for the daily delivery of antibacterial agents. In recent years, adjuncts to fluorides such as probiotics chlorhexidine have been proposed to in view of antiplaque and anticariogenic properties by means of reduction of bacterial count.

Aim: The study aimed to evaluate the anticariogenic activity and improvement in the oral health status of participants over a period of 45 days.

Materials and Methods: A single blinded, parallel group, randomized controlled clinical study was conducted among healthy adults. Thirty individuals were randomly allocated to two groups $(n=15)$ :

Group I - probiotic dentifrice (test group)

Group II - no intervention (control group)

Saliva samples were evaluated for Streptococcus mutans colony forming unit (CFU/ml of saliva) at baseline, 15th, 30th, $45^{\text {th }}$ day of follow-up. Paired t-test and one-way.

ANOVA were used to compare the mean differences of salivary S. mutans counts at the three time periods. Results: The mean S. mutans counts in saliva samples were significantly reduced in the treatment group at the 45th day of follow-up.

Conclusion: The test group exhibited antimicrobial activity by bringing about a significant reduction in the mean S. mutans colony counts at the 30 th day $\& 45^{\text {th }}$ day of follow-up.
\end{abstract}

(C) 2020 Published by Innovative Publication. This is an open access article under the CC BY-NC license (https://creativecommons.org/licenses/by-nc/4.0/)

\section{Introduction}

The dental plaque, which has been identified as a biofilm, is the primary etiological factor for most frequently occurring oral diseases, dental caries and periodontal diseases. ${ }^{1,2}$

Microbial biofilms are complex communities of bacteria and are common in the human body and in the environment. ${ }^{1-3}$ Dental biofilm cannot be eliminated, but it can be reduced and controlled through daily oral care. ${ }^{2}$

Since teeth comprise only $20 \%$ of the mouth's surfaces and the biofilm bacteria contained in oral mucosal reservoirs, the use of topical antimicrobials as an important adjunct to tooth brushing may also play a role in controlling

\footnotetext{
* Corresponding author.

E-mail address: dr.jasjit10@gmail.com (J. Kaur).
}

biofilm. ${ }^{3}$ Until today, the incorporation of chemical agents with antimicrobial activity into dental products has been proposed as a potential prophylactic method of reducing plaque-mediated disease. ${ }^{4}$

Probiotics can be defined as living microbes, or as food ingredients containing living microbes, that beneficially influence the health of the host when used in adequate numbers. 5

According to the World Health Organization (WHO), probiotics are defined as viable microorganisms that confer a health benefit when administered in sufficient doses. ${ }^{6,7}$

Commonly, most of the organisms ascribed as having probiotic properties belongs to the genera Lactobacillus and Bifidobacterium. ${ }^{8}$ 
Dental biofilm cannot be eliminated, but it can be reduced and controlled through daily oral care. Since teeth comprise only $20 \%$ of the mouth's surfaces and the biofilm bacteria contained in oral mucosal reservoirs, the use of topical antimicrobials as an important adjunct to tooth brushing may also play a role in controlling biofilm. Until today, the incorporation of chemical agents with antimicrobial activity into dental products has been proposed as a potential prophylactic method of reducing plaque-mediated disease.

Possible actions of probiotic bacteria in the oral environment would be a competition of binding sites, production of antimicrobial substances and activation and modulation of the immune response. Unlike probiotic-containing food or supplement product, probiotic-containing toothpaste is a relatively new concept in the prevention of oral infectious diseases such as caries and periodontal disease, and slowly accepted by the common toothpaste user Advantage of this kind of probiotic product is the opportunity for regular, daily, frequent intake of probiotics into the oral environment.

\section{Materials and Methods}

This was a single-centre, single blinded study comprising 30 patients. The study duration was 45 days, in which Plaque Index and Oral Hygiene index scores were measured at baseline, day 15 , day 30 and day 45 . The study protocol was initially submitted to the Ethical Committee of the Indraprastha Dental College, Ghaziabad India. After ethical approval was granted, subjects were selected from the outpatient section of the Department of Oral Medicine and Radiology, the Indraprastha Dental College after a written informed consent was taken from them.

\subsection{Inclusion criteria}

1. Patients in good health in age range 18- 65 yrs.

2. Good oral health with no active and untreated carious lesions.

\subsection{Exclusion criteria}

1. Subjects who have deep caries, defective restorations, chipped teeth, deep periodontal pockets.

2. Subjects who have received any antibiotic or antimicrobial agent or professional fluoride therapy within the last month.

3. Subjects with orthodontic appliances or bridge work that would interfere with evaluation.

4. If subjects are found to be allergic to any ingredients used in study or exhibitied any gross oral pathology, eating disorders, chronic disease, pregnancy $\&$ lactation, acute myocardial infarction within the past 6 months, use of pacemaker, uncontrolled metabolic disease, major psychiatric disorder, heavy smoking / alcohol abuse, any systemic disease or any disease requiring repeated or regular analgesia / antiinflammatory drugs or antihistamines.

30 participants of study were randomly divided into test and control groups comprising of 15 participants each. The test group used the probiotic toothpaste for a period of 45 days from starting whereas the control group continued to use the same toothpaste which they were already using.

All participants were demonstrated standard brushing technique and were instructed to brush with pea sized toothpaste twice daily.

\subsection{Sampling for microbiological analysis}

At the time of reporting, $2 \mathrm{ml}$ of salivary sample was collected from the participants in a sterile plastic container and sent for S.mutans colony count estimation to the Lal path lab which was collaborated with for conducting the microbiological tests. S.mutans was cultured in aerobic media and examined after $48 \mathrm{hrs}$ of overnight incubation and identification in Malditoff culture medium. Reports of these participants with S.mutans count expressed as colony forming units (CFU) $/ \mathrm{ml}$ were collected after 2 days from the lab.

Chair side evaluation of two clinical parameters for oral hygiene and plaque status were done using Oral Hygiene Index (OHI) and Plaque Index.

\subsection{Clinical parameters evaluated}

1. Oral Hygiene Index (OHI) given by Green and Vermillion in 1960 was recorded for all participants at all visits. Isolation was done using cotton rolls and teeth to be examined were air dried using 3 way syringe. Recording were made using mouth mirror and explorer for Calculus and Debris to calculate the Oral Hygiene Undex.

2. Plaque Index given by Silness and Loe in 1967 was also recorded for all patients at all visits by air drying the index teeth, applying disclosing agent and evaluating for the presence of plaque.

Both the groups were evaluated for these parameters at baseline, 15 days, 30 days and 45 days.

\subsection{Statistical methods}

Analysis was performed using SPSS software Version 21.0

Paired t-test and one-way ANOVA were used to compare the mean differences of salivary $\mathrm{S}$. mutans counts at the three time evaluations.

\section{Results}

Table 3 showed that there was significant mean comparison in OHI-S at 45 days of interval rest there was no significant 
Table 1: Mean difference of PI and OHI in test group by using probiotic toothpaste

\begin{tabular}{lcccc}
\hline Variable & Mean Difference & SD & t-value & p-value \\
PI & & & & 0.032 \\
O day- 15 days & -0.14 & 0.238 & -2.376 & 0.051 \\
15 days -30 days & -0.13 & 0.245 & -2.136 & 0.045 \\
30 days-45 days & 0.12 & 0.214 & 2.206 & 0.959 \\
OHI-S & & & & 0.918 \\
O day- 15 days & 0.01 & 0.735 & 0.053 & 0.105 \\
15 days -30 days & 0.01 & 0.666 & 3.379 & 0.470 \\
30 days-45 days & 0.42 & 0.47 & \\
\hline
\end{tabular}

There were statistically significant results found in relation to Plaque index and oral hygiene index, as both decreases significantly from baseline to 45 days.

Table 2: Mean difference of PI and OHI in control group by using probiotic toothpaste

\begin{tabular}{|c|c|c|c|c|}
\hline Variable & Mean Difference & SD & t-value & p-value \\
\hline \multicolumn{5}{|l|}{ PI } \\
\hline 0 day- 15 days & -0.91 & 0.275 & -1.284 & 0.220 \\
\hline 15 days -30 days & -0.11 & 0.232 & -1.858 & 0.084 \\
\hline 30 days -45 days & 0.17 & 0.239 & 2.876 & 0.012 \\
\hline \multicolumn{5}{|l|}{ OHI-S } \\
\hline 0 day- 15 days & -0.13 & 0.547 & -0.980 & 0.344 \\
\hline 15 days -30 days & -0.02 & 0.524 & -0.197 & 0.847 \\
\hline 30 days- 45 days & 0.17 & 0.493 & 1.381 & 0.189 \\
\hline
\end{tabular}

There were statistically significant results found in relation to Plaque index but not in oral hygiene index scores, from baseline to 45 days

Table 3: Comparison of Mean of PI and OHI in test and control group by using probiotic toothpaste

\begin{tabular}{lcccc}
\hline Variable & Mean + SD $($ Test) & Mean + SD $($ Control) & F-value & p-value \\
PI & & & 1.507 & 0.230 \\
0 day & $0.37+0.351$ & $0.52+0.281$ & 0.536 & 0.470 \\
15 days & $0.52+0.358$ & $0.61+0.297$ & 0.298 & 0.589 \\
30 days & $0.65+0.308$ & $0.72+0.332$ & 0.006 & 0.938 \\
45 days & $0.53+0.330$ & $0.54+0.211$ & 0.174 & 0.680 \\
OHI-S & & & 0.946 & 0.339 \\
0 day & $1.68+1.162$ & $1.83+0.792$ & 1.762 & 0.195 \\
15 days & $1.67+0.920$ & $1.97+0.761$ & 5.381 & 0.028 \\
30 days & $1.66+0.649$ & $2.00+0.767$ & $1.82+0.786$ & \\
45 days & $1.23+0.596$ & & & \\
\hline
\end{tabular}

results found in PI and OHI-S although the mean of PI and OHI-S was reduced at different intervals from baseline till to 45 days in test group as compared to control group.

Table 4 showed that theanticariogenic effect of toothpaste was significant in test group at 45 days as compared to control group, by assessing S. Mutans count.

\section{Discussion}

This study has been performed to determine the suppressive effect of three potential anticaries agents, i.e., fluoride, xylitol, and probiotic bacteria on bacteria related with caries in the saliva. It is believed that $\mathrm{S}$. mutans and Lactibacillus bacteria, which produce acids, have significant roles in the onset and development of dental caries. According to the definitions of the World Health Organization (WHO) and the American Food and Agricultural Organization (FAO),

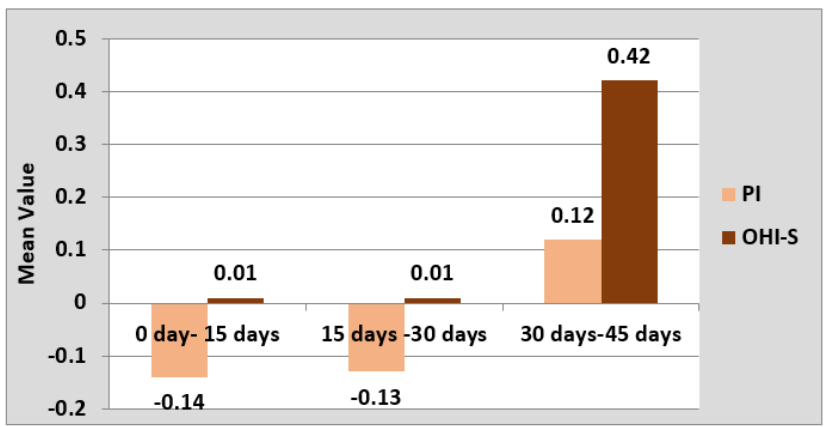

Fig. 1: Mean difference of PI and OHI -S in test and control group by using probiotic toothpaste in test group

probiotic bacteria are living organisms that are useful for health when taken in sufficient amounts. ${ }^{9}$ 
Table 4: Evaluation of anticariogenic activity of probiotic toothpaste by assessing S.mutans count

\begin{tabular}{|c|c|c|c|c|c|c|c|}
\hline CFU & 0 day & 1 & 2 & 3 & 4 & 5 & p-value \\
\hline $\begin{array}{l}\text { Test } \\
\text { Control }\end{array}$ & $\begin{array}{l}0(0 \%) \\
0(0 \%)\end{array}$ & $\begin{array}{l}0(0 \%) \\
0(0 \%)\end{array}$ & $\begin{array}{l}5(33.3 \%) \\
4(26.7 \%)\end{array}$ & $\begin{array}{c}3(20 \%) \\
4(26.7 \%)\end{array}$ & $\begin{array}{l}4(26.7 \%) \\
4(26.7 \%)\end{array}$ & $\begin{array}{l}3(20 \%) \\
3(20 \%)\end{array}$ & 0.968 \\
\hline $\begin{array}{l}\text { Test } \\
\text { Control }\end{array}$ & $\begin{array}{c}15 \text { days } \\
0(0 \%) \\
1(6.7 \%)\end{array}$ & $\begin{array}{c}3(20 \%) \\
2(13.3 \%)\end{array}$ & $\begin{array}{c}7(46.7 \%) \\
9(60 \%)\end{array}$ & $\begin{array}{c}5(33.3 \%) \\
3(20 \%)\end{array}$ & $\begin{array}{l}0(0 \%) \\
0(0 \%)\end{array}$ & $\begin{array}{l}0(0 \%) \\
0(0 \%)\end{array}$ & 0.583 \\
\hline $\begin{array}{l}\text { Test } \\
\text { Control }\end{array}$ & $\begin{array}{c}30 \text { Days } \\
0(0 \%) \\
0(0 \%) \\
45 \text { days }\end{array}$ & $\begin{array}{l}3(20 \%) \\
3(20 \%)\end{array}$ & $\begin{array}{l}8(53.3 \%) \\
12(80 \%)\end{array}$ & $\begin{array}{c}4(26.7 \%) \\
0(0 \%)\end{array}$ & $\begin{array}{l}0(0 \%) \\
0(0 \%)\end{array}$ & $\begin{array}{l}0(0 \%) \\
0(0 \%)\end{array}$ & 0.091 \\
\hline $\begin{array}{l}\text { Test } \\
\text { Control }\end{array}$ & $\begin{array}{l}0(0 \%) \\
0(0 \%)\end{array}$ & $\begin{array}{c}5(33.3 \%) \\
0(0 \%)\end{array}$ & $\begin{array}{c}4(26.7 \%) \\
1(6.7 \%)\end{array}$ & $\begin{array}{l}3(20 \%) \\
3(20 \%)\end{array}$ & $\begin{array}{l}0(0 \%) \\
0(0 \%)\end{array}$ & $\begin{array}{c}3(20 \%) \\
11(73.3 \%)\end{array}$ & 0.010 \\
\hline
\end{tabular}

Table 5: Test versus control group comparison on clinical parameters

\begin{tabular}{lcc}
\hline Variable & Test group & Control group \\
PI & & $53.9 \%$ \\
0 day- 15 days & $58.4 \%$ & $54.1 \%$ \\
15 days-30 days & $55.5 \%$ & $42.8 \%$ \\
30 days- 45 days & $44.9 \%$ & $51.8 \%$ \\
OHI-S & & $50.4 \%$ \\
0 day- 15 days & $49.8 \%$ & $47.6 \%$ \\
15 days-30 days & $49.8 \%$ & \\
30 days- 45 days & $42.5 \%$ & \\
\hline
\end{tabular}

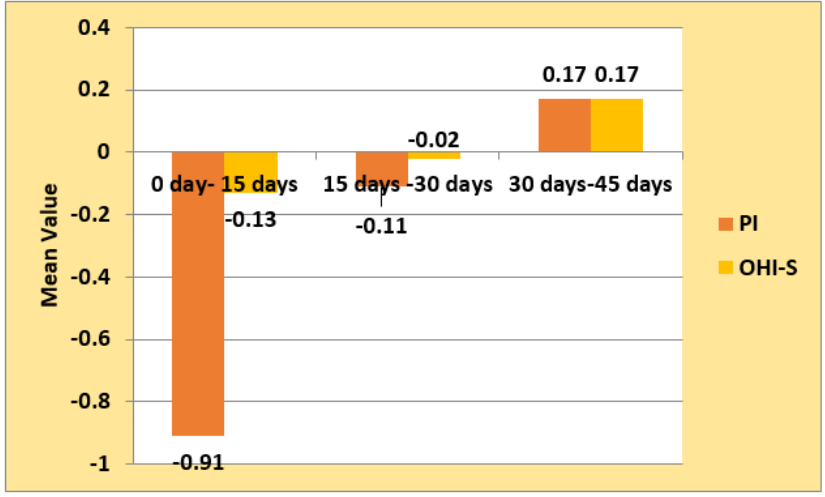

Fig. 2: Mean difference of PI and OHI -S in test and control group by using probiotic toothpaste in test group

There are many microorganisms that are called probiotics; Lactobacillus and Bifidobacterium are common probiotics. With the bacterial resistance against antibiotics being observed commonly, the idea of using probiotic treatment for oral health has emerged. Dental cavities, periodontal diseases, Candida albicans infections, and halitosis are among the target oral diseases that can be focused on.

If probiotics, which are in fact living organisms, are used in sufficient amount, they provide health benefits. Studies have been conducted in vivo thus far, and it has been claimed according to the conclusions that probiotic

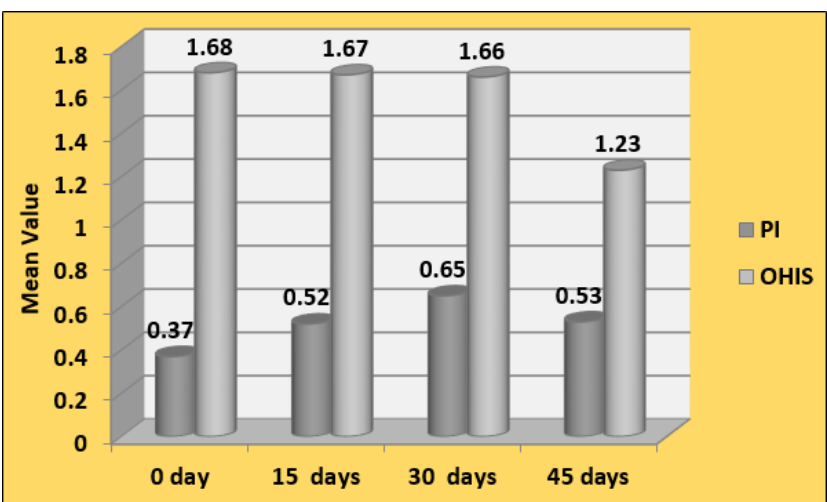

Fig. 3: Comparison of Mean of PI and $\mathrm{OHI}$ in test and control group by using probiotic toothpaste

Lactobacillus and bifidobacteria strains decrease the caries, which are related with the bacteria in the saliva. This newly developed product, which is a therapeutic innovation, can be beneficial to fight against dental caries and subsequently dental diseases by restoration of healthy microflora.

The test group in comparison to the control group showed a marked reduction in colony forming units count of $\mathrm{S}$ mutans when compared from baseline to 45 days.

The consistent fall in the colony count of $\mathrm{S}$ mutans is attributable to the rise in the concentration of bacillus coagulans in the oral cavity in those using the probiotic toothpaste. 


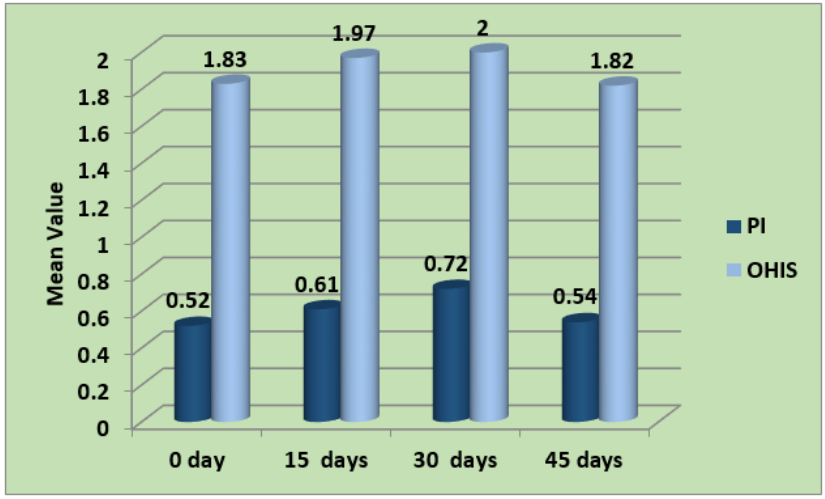

Fig. 4: Comparison of Mean of PI and OHI in test and control group by using probiotic toothpaste

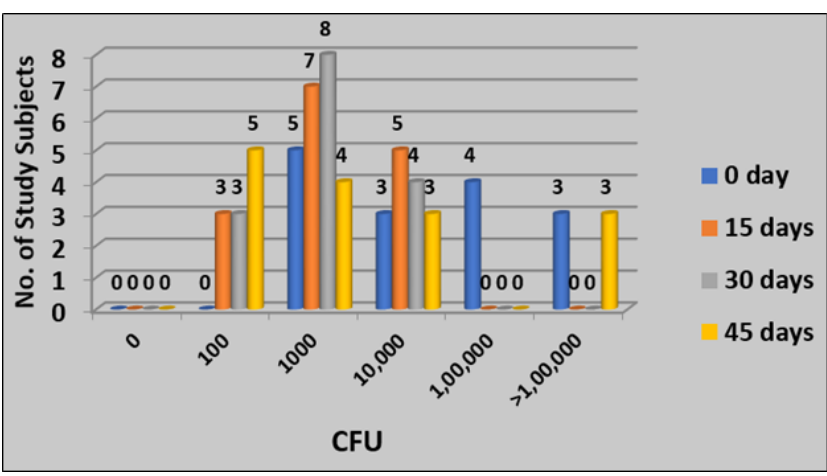

Fig. 5: Evaluation of anticariogenic activity of probiotic toothpaste by assessing S.mutans count

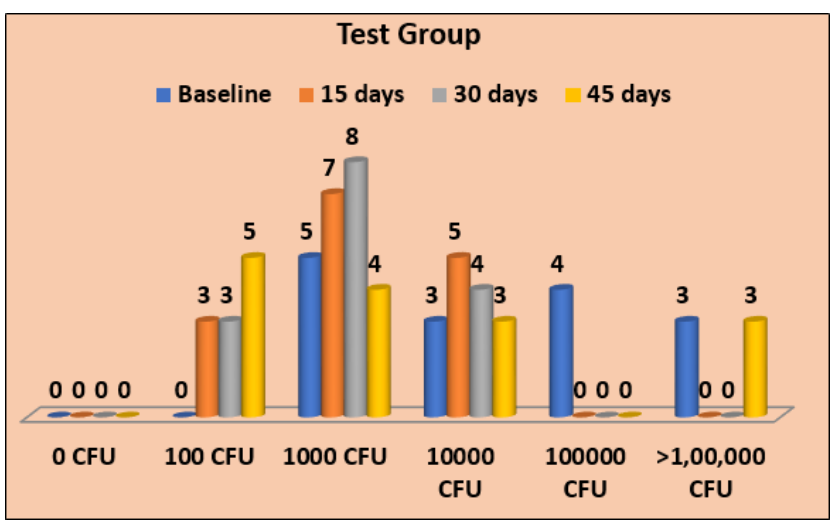

Fig. 6:

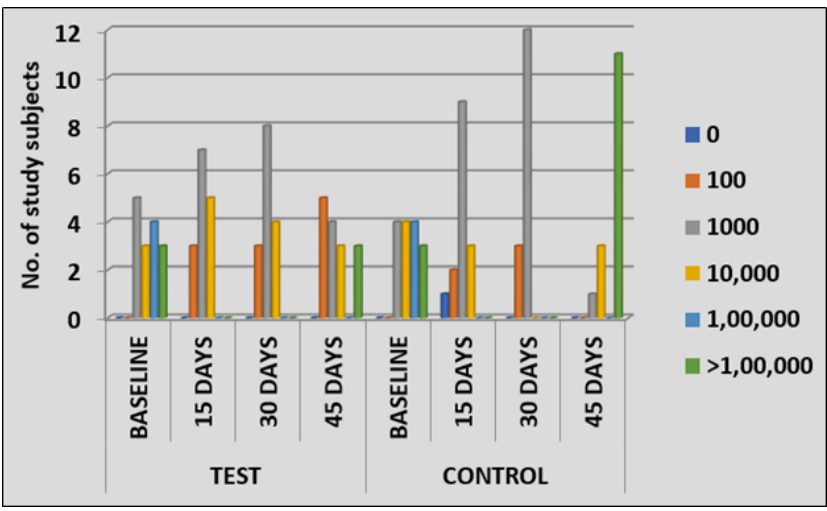

Fig. 7: CFU S mutans timeline comparison in study subjects

The fall in $\mathrm{S}$ mutans count concomitantly reflected in the other clinical parameters evaluated in the test group patients. These included Plaque Index and Oral hygiene index.

Reduction in $\mathrm{S}$ mutans was attributable to lowered plaque index values in the test population

Concomitantly better oral hygiene index was accounted for in them.

Bacillus coagulans is known to exert the following effects on the oral environment:

1. Bringing a balance of oral microbiota which also includes a reduction in streptococcus mutans activity. $\mathrm{S}$ mutans is known to be the principal microorganism responsible for causing dental caries via action on carbohydrates to produce acids, further leading to demineralization and dental caries progression.

2. An overall reduction in dental plaque caused due to reduction in harmful bacterial species and growth of beneficial bacterial species which prevented $\mathrm{pH}$ fall and dental decay.

Xylitol, a naturally occurring five-carbon sugar polyol, is a white crystalline carbohydrate known since a century ago. It has been widely studied during the last 40 years for its effect on dental caries. It is found naturally in fruit, vegetables, and berries and is artificially manufactured from xylan-rich plant materials such as birch and beechwood.5. Since a study conducted in Turku, Finland, evaluating the effectiveness of xylitol on dental plaque reduction in 1970, xylitol has been widely researched and globally accepted as a natural sweetener approved by the US Food and Drug Administration (FDA) and the American Academy of Pediatric Dentistry. ${ }^{10}$

Additive beneficial effect of xylitol which prevents the sucrose breakdown to acid formation, brings about $\mathrm{pH}$ balance and also exerts anticavity \& antimicrobial effect.

Sodium monofluorophosphate which acts as Fluoride source acts a key ingredient. Fluoride presence also creates anticaries effect as well as improvement in tooth integrity required for lon term maintainence of dental health. 
The uses of xylitol and fluoride in dentifrices have long been documented.

The influence of the fluoride in preventing caries is a well-known fact. Among the anti-caries substances, there are F-dentifrices, which are also widely-known. ${ }^{11}$ In many developed countries, reduction in caries has been achieved with toothpastes containing fluoride. ${ }^{12}$ Dentifrices that contain fluoride are recommended for everybody from every age group. ${ }^{13}$ Fluoride is plentiful in the mouth and has considerable bioavailability because of its solubility in ionic (free) form (F- of $\mathrm{NaF}$ ) or in ionizable form (MFP). The anticaries activity is ensured by the bioavailable form of fluoride. ${ }^{14}$

Xylitol, a natural sugar alcohol is used as a sweetener. To prevent caries, the use of xylitol is approved by the American Academy of Pediatric Dentistry (AAPD) 7 The fact that xylitol products have bacteriostatic effect on $S$. mutans has been documented in clinical trials.

Only one study, which was conducted in vitro, claims that xylitol toothpastes have a potential in preventing tooth decays.

\section{Conclusion}

This study was aimed to reveal the influence of fluoride, xylitol and probiotic on salivary S. mutans and levels, also on the oral hygiene

As per the results obtained there were a reduction with regard to the microbial salivary counts of the subject population using probiotic toothpaste. Also, other parameters showed a significant change in oral hygiene improvement in terms of reduction of plaque.

It could be recommended as a therapeutic toothpaste, especially in individuals who are at high risk for caries.

\section{Source of Funding}

Purexa Global Pvt Ltd.

\section{Conflict of Interest}

None.

\section{References}

1. Haffajee AD, Socransky SS. Microbial etiological agents of destructive periodontal diseases. Periodontol. 1994;5:78-111.
2. Page RC. The etiology and pathogenesis of periodontitis. Compend Contin Educ Dent. 2002;23:11-4.

3. Gamboa F, Estupinan M, Galindo A. Presence of Streptococcus mutans in saliva and its relationship with dental caries: antimicrobial susceptibility of the isolates. Univ Sci. 2004;9:23-7.

4. Mager DL, Ximenez-Fyvie LA, Haffajee AD, Socransky SS. Distribution of selected bacterial species on intraoral surfaces. J Clin Periodontol. 2003;30(7):644-54.

5. Ashwell M. Concept of functional foods. Europe, B-1200 Brussels, Belgium: International Life Sciences Institute; 2002.

6. Food and Agriculture Organization of the United Nations/World Health Organization FAO/WHO. Health and Nutritional Properties of Probiotics in Food including Powder Milk with Live Lactic Acid Bacteria; 2001. Available from: http://www.who.Int/foodsafety/ publications/ts_management/en/probiotics.pdt

7. Food and Agriculture Organization of the United Nations/World Health Organization FAO/WHO. Guidelines for the Evaluation of Probiotics in Food; Joint FAO/WHO Working Group on Drafting Guidelines for the Evaluation of Probiotics in Food: London, Ontario, Canada; 2002.

8. Stomatova I, Meurman JH. Probiotics:Health benefits in the Mouth. Am J Dent. 2009;22:329-38.

9. Joint FAO/WHO Working Group Report on Drafting Guidelines for the Evaluation of Probiotics in Food London, Ontario, Canada; 2002.

10. American Academy of Pediatric Dentistry. Policy on the use of xylitol in caries prevention. Pediatr Dent. 2010;32:36-8.

11. Cate JMT. Current concepts on the theories of the mechanism of action of fluoride. Acta Odontol Scand . 1999;57(6):325-9.

12. Cury JA, Tenuta LMA, Ribeiro CCC, Leme AFP. The importance of fluoride dentifrices to the current dental caries prevalence in Brazil. Braz Dent J. 2004;15(3):167-74.

13. Bardal PA, Olympio KP, Cardoso VEDS, Bastos JRDM, Buzalaf MA. Evaluation of total $\mathrm{pH}$ and soluble and ionic fluoride concentrations in dentifrices commercially available in Brazil. Oral Health Prev Dent. 2003;1:283-9.

14. Tenuta LMA, Cury JA. Fluoride: its role in dentistry. Braz Oral Res. 2010;24(suppl 1):9-17.

\section{Author biography}

Jasjit Kaur Manager- Clinical Research and Product Development

Rahul Paul Professor and HOD

Divya Gupta Senior Lecturer

Aastha Manchanda Associate Professor

Geetika Arora Associate Professor

Cite this article: Kaur J, Paul R, Gupta D, Manchanda A, Arora G

Clinical efficacy of a probiotic fluoride dentifrice: A comparitive clinical and microbiologic study. Int J Oral Health Dent 2020;6(2):131-136. 